\title{
Patient satisfaction with point-of-care testing in general practice
}

Caroline O Laurence, Angela Gialamas, Tanya Bubner, Lisa Yelland, Kristyn Willson, Phil Ryan, Justin Beilby, and the Point of Care Testing in General Practice Trial Management Group

\section{ABSTRACT}

Background

Point-of-care testing is increasingly being used in general practice to assist GPs in their management of patients with chronic disease. However, patient satisfaction and acceptability of point-of-care testing in general practice has not been widely studied.

Aim

To determine if patients are more satisfied with pointof-care testing than with pathology laboratory testing for three chronic conditions.

Design of study

As part of a large multicentre, randomised, controlled trial assessing the use of point-of-care testing in Australian general practice, satisfaction was measured for patients having pathology testing performed by point-of-care testing devices or pathology laboratories. Patients in the trial were managed by GPs for diabetes, hyperlipidaemia, and/or anticoagulant therapy.

\section{Method}

Patient satisfaction was measured using level of agreement with a variety of statements at the end of the study with a patient satisfaction questionnaire for both the intervention and control groups. Analysis was performed using a mixed model analysis of variance (ANOVA) with allowance for clustering at the practice level following Box-Cox transformations of the data to achieve normality.

\section{Results}

Overall, intervention patients reported that they were satisfied with point-of-care testing. In comparison with the control group, the intervention group had a higher level of agreement than control patients with statements relating to their satisfaction with the collection process $(P<0.001)$ and confidence in the process $(P<0.001)$. They also viewed point-of-care testing as strengthening their relationship with their GP $(P=0.010)$ and motivational in terms of better managing their condition $(P<0.001)$.

\section{Conclusion}

The results from this trial support patient satisfaction and acceptability of point-of-care testing in a general practice setting.

Keywords general practice; patients; point-of-care systems; satisfaction.

\section{IINTRODUCTION}

Point-of-care testing is defined as any test taken by or on behalf of the treating doctor on-site at the time of consultation, which allows the test result to be used to make immediate decisions about patient treatment. ${ }^{1}$ It has the potential to be useful in general practice in a number of areas including clinical management, monitoring of conditions, and medication compliance, fostered by more efficient and regular pathology testing. From a patient perspective, point-of-care testing may lead to improved compliance with disease management, greater convenience, and reduced cost. The Point of Care Testing in General Practice Trial has shown that for most of the tests considered, point-of-care testing resulted in the same or better therapeutic control compared to pathology laboratory testing. ${ }^{2,3}$

Patient satisfaction with point-of-care testing forms an important part of the assessment of introducing this technology in general practice. Patient satisfaction and acceptability of point-of-care testing in a general practice setting has not been widely studied. Based on the available evidence, the

CO Laurence, BA (Hons), MHSM, PhD, senior research fellow, A Gialamas, BHSc, research associate, TK Bubner, BSocSc (HumServ), Grad Dip Hlth Serv Mg; research officer, Discipline of General Practice; LN Yelland, BMa\&CompSci(Hons), statistician; P Ryan, MB BS, professor and director; KJ Willson, BSc(Hons), statistician, Data Management \& Analysis Centre, Discipline of Public Health, School of Population Health and Clinical Practice; JJ Beilby, MB BS, MD, FRACGP, MPH MD, DRACOG, DA, Executive Dean, Faculty of Health Sciences, The University of Adelaide, North Terrace, Adelaide, SA 5005, Australia.

Address for correspondence

Caroline Laurence, Discipline of General Practice, The University of Adelaide, Adelaide SA, 5005, Australia. E-mail: caroline.laurence@adelaide.edu.au

Submitted: 29 January 2009; Editor's response: 16 April 2009; final acceptance: 23 July 2009.

(C) British Journal of General Practice

This is the full-length article of an abridged version published in print. Cite this article as: Br J Gen Pract 2010; DOI: 10.3399/bjgp10X483508. 
findings are mixed, with some studies suggesting patients' preference for point-of-care testing, ${ }^{4,5}$ and improved satisfaction with their health care after the introduction of point-of-care testing, ${ }^{6-8}$ while other studies have found no significant difference..$^{9,10}$ There have been only two randomised trials that have examined patient acceptability and satisfaction with point-of-care testing in a general practice setting. ${ }^{9,11}$ Overall, the literature relating to patient satisfaction and acceptability of point-of-care testing has generally been positive but there has been a lack of comparative analyses and so results may overestimate patient satisfaction.

The aim of this study was to determine if patients are more satisfied with point-of-care testing than with pathology laboratory testing for three chronic conditions.

\section{METHOD}

This study was part of the Point of Care Testing in General Practice Trial which was conducted in 2005-2007. It was an Australian government-funded multicentre, cluster, randomised controlled trial (RCT) to determine the safety, clinical effectiveness, costeffectiveness, and satisfaction of point-of-care

\section{How this fits in}

Few RCTs have investigated patient satisfaction with point of care testing in general practice and most of the studies that do exist provide only a descriptive analysis using a small sample size. Additionally, there are differing results across the few studies undertaken in this area. The results from this large RCT provide evidence of patient satisfaction and acceptability of point of care testing for three chronic conditions, an important aspect to consider if point of care testing is made widely available.

testing in general practice. ${ }^{2}$ Briefly, practices were recruited from three geographic locations (urban, rural, and remote), and from these practices patients were recruited with diabetes or hyperlipidaemia, and/or were on anticoagulant therapy. The trial aimed to recruit 30 practices per group, providing 1262 patients on anticoagulant therapy, 894 patients with hyperlipidaemia, and 1262 patients with diabetes per group. These patient numbers would provide $80 \%$ power, assuming a design effect of 2 for analysis of the main outcome measure relating to therapeutic control. Practice and participant progress throughout the trial is provided in a CONSORT (Consolidated

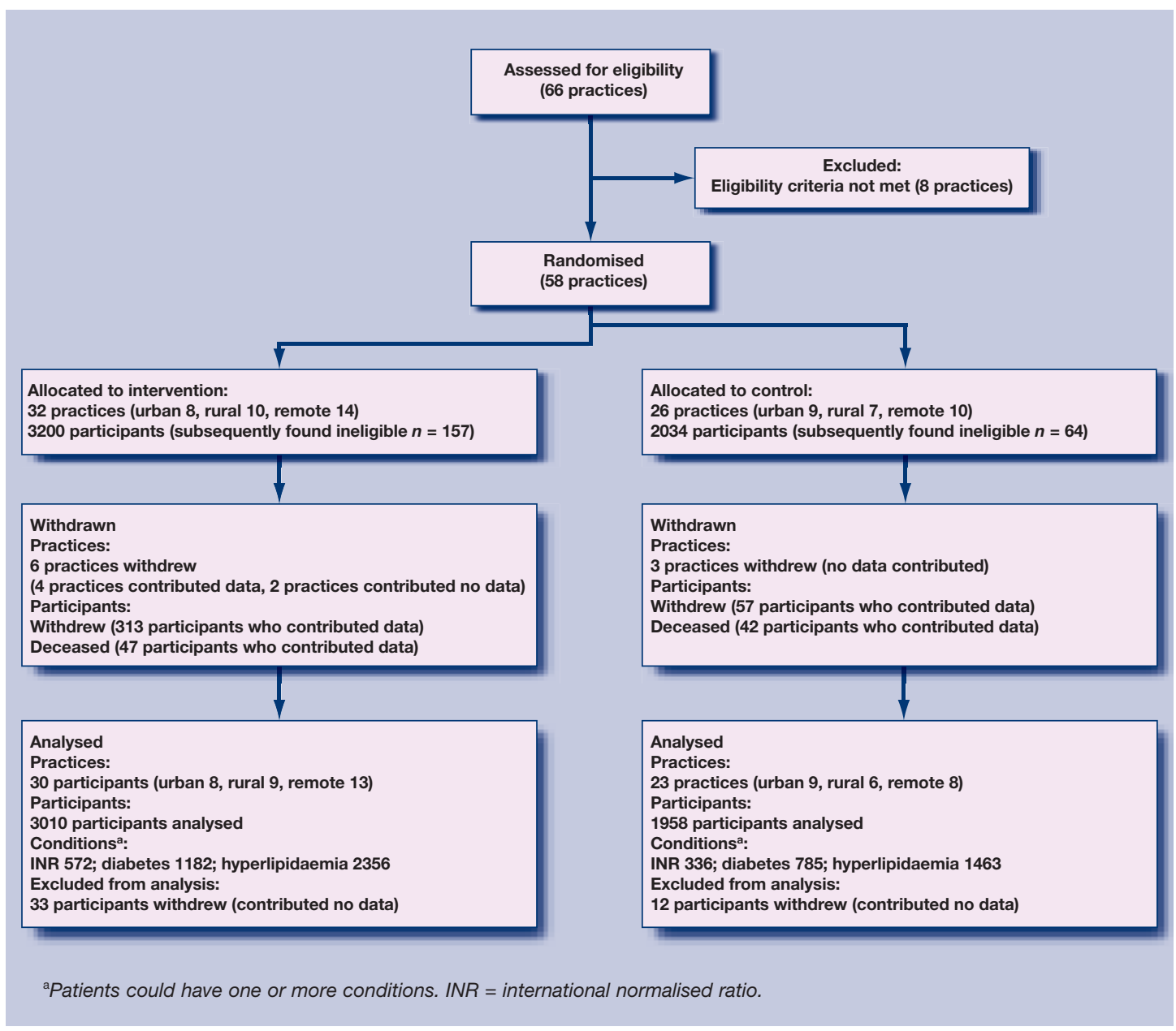

Figure 1. CONSORT

diagram showing flow of clusters and participants' progress through the trial. 
Table 1. Summary characteristics of patients.

\begin{tabular}{lccc} 
Characteristics & Intervention, $(n=3010)$ & Control, $(n=1958)$ & Total, $(n=4968)$ \\
\hline Male sex, frequency (\%) & $1630(54.2)$ & $1018(52.0)$ & $2648(53.3)$ \\
\hline Age group, years: frequency (\%) & & & \\
$18-39$ & $52(1.7)$ & $21(1.1)$ & $73(1.5)$ \\
$40-49$ & $199(9.6)$ & $109(5.6)$ & $308(6.2)$ \\
$50-59$ & $573(19.0)$ & $335(17.1)$ & $908(18.3)$ \\
$60-69$ & $1015(33.7)$ & $604(30.8)$ & $1619(32.6)$ \\
$70-79$ & $867(28.8)$ & $680(34.7)$ & $1547(31.1)$ \\
$\geq 80$ & $304(10.1)$ & $209(10.7)$ & $513(10.3)$ \\
\hline Median age (interquartile range), years & $66.0(59.0-74.0)$ & $68.0(60.0-75.0)$ & $67.0(59.0-75.0)$ \\
\hline Geographic region, frequency (\%) & & & \\
Urban & $897(29.8)$ & $840(42.9)$ & $1737(35.0)$ \\
Rural & $917(30.5)$ & $447(22.8)$ & $1364(27.5)$ \\
Remote & $1196(39.7)$ & $671(34.3)$ & $1867(37.6)$ \\
\hline Condition, frequency (\%) & & & \\
Anticoagulant therapy & & $372(19.0)$ & $944(19.0)$ \\
Diabetes & $572(19.0)$ & $785(40.1)$ & $1967(39.6)$ \\
Hyperlipidaemia & $1182(39.3)$ & $1463(74.7)$ & $3819(76.9)$ \\
\hline
\end{tabular}

apatients could have more than one condition.

Standards of Reporting Trials) diagram in Figure 1. A total of 4968 patients contributed to the analysis, with 3010 and 1958 patients in the intervention and control groups respectively, and their characteristics are provided in Table 1.

Patients in the intervention group had their samples taken in the practice, with pathology testing performed using three point-of-care testing devices located in the practices. Patients in the control group had their samples taken either in the practice and forwarded to the local laboratories for pathology testing or at the local laboratory or collection centre. For both groups there was no cost to the patient for the pathology testing. The trial has been described elsewhere, providing in detail the methodology, rationale, recruitment process, and baseline patient characteristics. ${ }^{2}$

Satisfaction was measured at the end of the study for both intervention and control patients using level of agreement with a variety of statements in a patient satisfaction questionnaire. A total of 4573 questionnaires were distributed. Questionnaires were not sent to 395 patients because of practice/patient withdrawal, death, or relocation. Eight statements from the questionnaire were analysed; these addressed six categories: collection process, confidence in the process, confidence in the result, convenience, cost, and disease management. The statements were based on similar studies, or developed specifically for this study. The statements were reviewed by the Point of Care Testing Trial Management Committee, and piloted with a sample of patients.

Participants were asked to indicate how strongly they agreed/disagreed with the statements concerning their satisfaction with aspects of pointof-care testing, using a visual analogue scale.

\section{Statistical analysis}

Since the data were not normally distributed, Box-Cox transformations were applied; ${ }^{12}$ different transformation parameters were required for each statement, ranging from 0.12 to 0.49 . For all satisfaction categories except confidence in the process, the data were negatively skewed and hence needed to be reflected before the transformation was applied. In the transformed data, if the data were not reflected then a larger value indicates a higher level of agreement. However, if the data were reflected then a larger value indicates a lower level of agreement.

As not all patients completed the questionnaire, the nature of the missing data was investigated and there was evidence to suggest that they were not missing completely at random. Multiple imputation was used to impute the missing (transformed) values using firstly the Markov Chain Monte Carlo method to produce a monotone missing data pattern, and secondly the regression method to fill in the remaining missing values. Analysis was performed on each 10 completed datasets and the results were combined.

Analysis was performed on the transformed data for each statement using a mixed model analysis of variance (ANOVA), with adjustment for age and sex and allowance for clustering at the practice level. Statistical significance was assessed at the 0.05 level and results are presented as medians based on the untransformed data, adjusted means based on the transformed data, differences in adjusted means, and 
Table 2. Between-group comparisons of patient satisfaction for all conditions.

\begin{tabular}{|c|c|c|c|c|c|}
\hline Areas & Statements & $\begin{array}{l}\text { Intervention median } \\
\text { satisfaction score } \\
\text { (mean transformed } \\
\text { satisfaction score) }\end{array}$ & $\begin{array}{l}\text { Control median } \\
\text { satisfaction score } \\
\text { (mean transformed } \\
\text { satisfaction score) }\end{array}$ & $\begin{array}{l}\text { Difference (intervention } \\
\text { - control) in mean } \\
\text { transformed satisfaction } \\
\text { score }(95 \% \mathrm{Cl})\end{array}$ & $P$-value \\
\hline Collection process & $\begin{array}{l}\text { I would rather have blood taken by a } \\
\text { finger prick than by needle in my arm }\end{array}$ & $7.8(0.92)$ & $5.1(1.64)$ & $-0.73(-0.89$ to -0.57$)$ & $<0.001$ \\
\hline $\begin{array}{l}\text { Confidence in the } \\
\text { process }\end{array}$ & $\begin{array}{l}\text { Laboratories have better hygiene } \\
\text { than point-of-care testing }\end{array}$ & $4.3(1.65)$ & $4.6(2.07)$ & $-0.43(-0.62$ to -0.23$)$ & $<0.001$ \\
\hline $\begin{array}{l}\text { Confidence in } \\
\text { the results }\end{array}$ & $\begin{array}{l}\text { I have confidence in the information given } \\
\text { by my GP or practice regarding my } \\
\text { pathology test result }\end{array}$ & $9.0(0.06)$ & $8.9(0.18)$ & $-0.12(-0.21$ to -0.03$)$ & 0.010 \\
\hline Convenience & $\begin{array}{l}\text { Not having to travel to an outside } \\
\text { laboratory would be convenient }\end{array}$ & $8.9(0.17)$ & $8.7(0.36)$ & $-0.20(-0.34$ to -0.05$)$ & 0.009 \\
\hline Cost & $\begin{array}{l}\text { Outside pathology laboratories involves } \\
\text { extra time and transport costs }\end{array}$ & $8.5(0.44)$ & $8.6(0.39)$ & $0.06(-0.11$ to 0.23$)$ & 0.510 \\
\hline \multirow[t]{3}{*}{ Disease management } & $\begin{array}{l}\text { Having immediate feedback of the test } \\
\text { result for my condition was important as } \\
\text { it allowed/would allow me to discuss the } \\
\text { management of my condition with my GP }\end{array}$ & $9.0(0.12)$ & $8.7(0.30)$ & $-0.18(-0.30$ to -0.06$)$ & 0.003 \\
\hline & $\begin{array}{l}\text { I am/would be more motivated to look } \\
\text { after my condition because of regular } \\
\text { point-of-care testing }\end{array}$ & $8.9(0.29)$ & $8.2(0.64)$ & $-0.36(-0.49$ to -0.22$)$ & $<0.001$ \\
\hline & $\begin{array}{l}\text { Point-of care-testing strengthened/would } \\
\text { strengthen my relationship with my GP }\end{array}$ & $8.3(0.52)$ & $8.1(0.72)$ & $-0.20(-0.35$ to -0.05$)$ & 0.010 \\
\hline
\end{tabular}

Note: a lower transformed score indicates a higher level of agreement except for the hypothesis relating to confidence in the process, where a higher transformed score indicates a higher level of agreement.

95\% two-sided confidence intervals (Cls). The analysis was repeated with a location effect (urban, rural, or remote) as well as an interaction between treatment group and location, to test for evidence of effect modification by geographic location. Analyses were performed overall and separately by condition. All analyses were performed using SAS (version 9.1.3).

\section{RESULTS}

An overall response rate of $88.0 \%$ was achieved, with response rates of $87.2 \%$ and $89.0 \%$ in the intervention and control groups respectively. The results for the level of agreement with each of the eight statements for all patients are provided in Table 2 and Table 3. For all statements, the intervention group showed high levels of satisfaction with pointof-care testing.

When comparing levels of satisfaction between the intervention and control groups, intervention patients showed significantly higher levels of agreement with the following statements: 'I would rather have blood taken by a finger prick than by needle in my arm' $(P<0.001)$; 'I have confidence in the information given by my GP or practice regarding my pathology test result' $(P=0.010)$; 'Not having to travel to an outside laboratory would be convenient' $(P=0.009)$; 'Having immediate feedback of the test result for my condition was important as it allowed/would allow me to discuss the management of my condition with my GP' $(P=0.003)$; 'I am/would be more motivated to look after my condition because of regular pointof-care testing' $(P<0.001)$; and 'Point-of-care testing strengthened/would strengthen my relationship with my GP' $(P=0.010)$. Control patients agreed more with the statement 'Laboratories have better hygiene than point-of-care testing' $(P<0.001)$ compared to the intervention group. Agreement with the statement 'Outside pathology laboratories involves extra time and transport costs' was similar in both treatment groups $(P=0.510)$.

Patients on anticoagulant therapy showed a greater difference between intervention and control groups compared to patients with diabetes and hyperlipidaemia for the categories relating to the collection process, convenience, and disease management (Table 3). For all other statements, similar results were found when the data were analysed separately by condition.

There was no evidence of effect modification by geographic location for any of the statements.

\section{DISCUSSION}

\section{Summary of main findings}

The trial found that patients using point-of-care testing were satisfied. Intervention patients on average were more satisfied than control patients with regard to the point-of-care testing process, the convenience of not travelling to an outside 
Table 3. Between-group comparisons of patient satisfaction by condition.

\begin{tabular}{|c|c|c|c|c|c|c|}
\hline Areas & Statements & $\begin{array}{l}\text { Patient } \\
\text { conditions/group }\end{array}$ & $\begin{array}{c}\text { Intervention } \\
\text { median } \\
\text { satisfaction score } \\
\text { (mean transformed } \\
\text { satisfaction score) }\end{array}$ & $\begin{array}{c}\text { Control } \\
\text { median } \\
\text { satisfaction score } \\
\text { (mean transformed } \\
\text { satisfaction score) }\end{array}$ & $\begin{array}{c}\text { Difference } \\
\text { (intervention - } \\
\text { control) in mean } \\
\text { transformed satisfaction } \\
\text { score }(95 \% \mathrm{Cl})\end{array}$ & $P$-value \\
\hline \multirow[t]{4}{*}{ Collection process } & \multirow{4}{*}{$\begin{array}{l}\text { I would rather have blood } \\
\text { taken by a finger prick than } \\
\text { by needle in my arm }\end{array}$} & All conditions & $7.8(0.92)$ & $5.1(1.64)$ & $-0.73(-0.89$ to -0.57$)$ & $<0.001$ \\
\hline & & Anticoagulant therapy & $8.7(0.36)$ & $5.0(1.60)$ & $-1.24(-1.49$ to -0.98$)$ & $<0.001$ \\
\hline & & Diabetes & $7.8(0.87)$ & $5.9(1.46)$ & $-0.59(-0.80$ to -0.39$)$ & $<0.001$ \\
\hline & & Hyperlipidaemia & $7.7(0.98)$ & $5.0(1.68)$ & $-0.70(-0.87$ to -0.53$)$ & $<0.001$ \\
\hline \multirow{4}{*}{$\begin{array}{l}\text { Confidence in the } \\
\text { process }\end{array}$} & \multirow{4}{*}{$\begin{array}{l}\text { Laboratories have better hygiene } \\
\text { than point-of-care testing }\end{array}$} & All conditions & $4.3(1.65)$ & $4.6(2.07)$ & $-0.43(-0.62$ to -0.23$)$ & $<0.001$ \\
\hline & & Anticoagulant therapy & $3.4(1.41)$ & $4.8(2.00)$ & $-0.59(-0.87$ to -0.30$)$ & $<0.001$ \\
\hline & & Diabetes & $4.3(1.71)$ & $4.6(2.09)$ & $-0.39(-0.67$ to -0.11$)$ & 0.007 \\
\hline & & Hyperlipidaemia & $4.3(1.66)$ & $4.7(2.09)$ & $-0.43(-0.63$ to -0.23$)$ & $<0.001$ \\
\hline \multirow{4}{*}{$\begin{array}{l}\text { Confidence in the } \\
\text { results }\end{array}$} & \multirow{4}{*}{$\begin{array}{l}\text { I have confidence in the } \\
\text { information given by my GP or } \\
\text { practice regarding my } \\
\text { pathology test result }\end{array}$} & All conditions & $9.0(0.06)$ & $8.9(0.18)$ & $-0.12(-0.21$ to -0.03$)$ & 0.010 \\
\hline & & Anticoagulant therapy & py $9.1(-0.05)$ & $8.9(0.12)$ & $-0.16(-0.32$ to -0.01$)$ & 0.039 \\
\hline & & Diabetes & $9.1(-0.01)$ & $8.9(0.18)$ & $-0.18(-0.32$ to -0.04$)$ & 0.010 \\
\hline & & Hyperlipidaemia & $8.9(0.08)$ & $8.9(0.20)$ & $-0.12(-0.21$ to -0.02$)$ & 0.018 \\
\hline \multirow[t]{4}{*}{ Convenience } & \multirow{4}{*}{$\begin{array}{l}\text { Not having to travel to an outside } \\
\text { laboratory would be convenient }\end{array}$} & All conditions & $8.9(0.17)$ & $8.7(0.36)$ & $-0.20(-0.34$ to -0.05$)$ & 0.009 \\
\hline & & Anticoagulant therapy & $9.0(0.04)$ & $8.7(0.37)$ & $-0.33(-0.58$ to -0.07$)$ & 0.012 \\
\hline & & Diabetes & $8.9(0.14)$ & $8.8(0.33)$ & $-0.19(-0.36$ to -0.01$)$ & 0.033 \\
\hline & & Hyperlipidaemia & $8.8(0.20)$ & $8.5(0.38)$ & $-0.18(-0.34$ to -0.03$)$ & 0.021 \\
\hline \multirow[t]{4}{*}{ Cost } & \multirow{4}{*}{$\begin{array}{l}\text { Outside pathology laboratories } \\
\text { involves extra time and } \\
\text { transport costs }\end{array}$} & All conditions & $8.5(0.44)$ & $8.6(0.39)$ & $0.06(-0.11$ to 0.23$)$ & 0.51 \\
\hline & & Anticoagulant therapy & $8.7(0.38)$ & $8.8(0.42)$ & $-0.04(-0.33$ to 0.24$)$ & 0.76 \\
\hline & & Diabetes & $8.5(0.41)$ & $8.6(0.35)$ & $0.06(-0.13$ to 0.26$)$ & 0.54 \\
\hline & & Hyperlipidaemia & $8.4(0.46)$ & $8.5(0.41)$ & 0.05 (-0.12 to 0.22$)$ & 0.56 \\
\hline \multirow[t]{12}{*}{ Disease management } & \multirow{4}{*}{$\begin{array}{l}\text { Having immediate feedback of the } \\
\text { test result for my condition was } \\
\text { important as it allowed/would allow } \\
\text { me to discuss the management } \\
\text { of my condition with my GP }\end{array}$} & All conditions & $9.0(0.12)$ & $8.7(0.30)$ & $-0.18(-0.30$ to -0.06$)$ & 0.003 \\
\hline & & Anticoagulant therapy & py $9.2(-0.10)$ & $9.0(0.27)$ & $-0.37(-0.59$ to -0.15$)$ & $<0.001$ \\
\hline & & Diabetes & $9.1(-0.00)$ & $8.8(0.25)$ & $-0.26(0.41$ to -0.11$)$ & $<0.001$ \\
\hline & & Hyperlipidaemia & $9.0(0.17)$ & $8.6(0.34)$ & $-0.17(-0.29$ to -0.05$)$ & 0.006 \\
\hline & \multirow{4}{*}{$\begin{array}{l}\text { I am/would be more motivated to } \\
\text { look after my condition because } \\
\text { of regular point-of-care testing }\end{array}$} & All conditions & $8.9(0.29)$ & $8.2(0.64)$ & $-0.36(-0.49$ to -0.22$)$ & $<0.001$ \\
\hline & & Anticoagulant therapy & $9.1(0.11)$ & $8.6(0.59)$ & $-0.48(-0.70$ to -0.25$)$ & $<0.001$ \\
\hline & & Diabetes & $9.0(0.22)$ & $8.2(0.59)$ & $-0.37(-0.55$ to -0.20$)$ & $<0.001$ \\
\hline & & Hyperlipidaemia & $8.9(0.32)$ & $8.2(0.66)$ & $-0.34(-0.49$ to -0.19$)$ & $<0.001$ \\
\hline & \multirow{4}{*}{$\begin{array}{l}\text { Point-of-care testing strengthened/ } \\
\text { would strengthen my relationship } \\
\text { with my GP }\end{array}$} & All conditions & $8.3(0.52)$ & $8.1(0.72)$ & $-0.20(-0.35$ to -0.05$)$ & 0.010 \\
\hline & & Anticoagulant therapy & $8.7(0.37)$ & $8.4(0.65)$ & $-0.28(-0.52$ to -0.04$)$ & 0.024 \\
\hline & & Diabetes & $8.7(0.41)$ & $8.3(0.66)$ & $-0.25(-0.43$ to -0.06$)$ & 0.010 \\
\hline & & Hyperlipidaemia & $8.3(0.55)$ & $8.0(0.75)$ & $-0.20(-0.35$ to -0.05$)$ & 0.008 \\
\hline
\end{tabular}

Note: a lower transformed score indicates a higher level of agreement except for the hypothesis relating to confidence in the process, where a higher transformed score indicates a higher level of agreement.

laboratory, and disease management regardless of condition. While these results were statistically significant, differences were small with the exception of the point-of-care testing process. Satisfaction was not influenced by geographic location.

The results indicate that while patient satisfaction with pathology testing was high regardless of the method of testing, higher satisfaction levels were found when using point-of-care testing. This provides some evidence that point-of-care testing, when used in general practice, is acceptable for patients.

Higher levels of satisfaction among the intervention group patients compared to control patients were found for disease management, with intervention patients agreeing more on average with the statements that they were more motivated to look after their condition, that having immediate feedback of the test result was important as it allowed the discussion of the management of their condition with their GP, and that point-of-care testing strengthened their relationship with their GP. Compared to patients in the control group, patients in the intervention group showed a significantly greater level of agreement with the statements that they were confident in the test results and that they would rather have blood taken by finger prick than by a needle in their arm.

\section{Strengths and limitations of the study}

The strengths of this analysis are that a large number of patients were surveyed with a high response rate. 
Additionally, this study has a much larger sample size than any comparative study, it covered three conditions, and was part of one of the largest RCTs in point-of-care testing in a primary care setting.

A limitation of the study is that the levels of satisfaction found in the intervention patients may result from simply being part of a trial rather than being attributable to the intervention; this is known as the Hawthorne effect. This is acknowledged, but it should also be noted that the trial ran for 18 months and therefore it is reasonable to assume that this effect would have dissipated over this period of time. Secondly, the study developed its own questionnaire regarding satisfaction, as there was no validated survey instrument available that was suitable for all the conditions investigated. However, in designing the questionnaire, the focus was on areas or questions used in other studies. Additionally, for most of the statements, the differences in satisfaction levels were small and the statistical significance of the results may be due to the large sample size rather than reflecting important differences between the treatment groups. However, the difference in satisfaction levels with regard to the collection process was large, suggesting that pointof-care testing can have a meaningful impact on satisfaction.

Finally, the number of intervention and control patients recruited to the study differed substantially (3010 versus 1958). This was most likely due to differences between groups in motivation to participate. However, the sample size achieved in the control group is still large, making this one of the largest studies to date comparing point-of-care testing to pathology laboratory testing.

\section{Comparison with existing literature}

These results demonstrate agreement with other published literature regarding patient satisfaction and acceptability of point-of-care testing. ${ }^{6,11}$ Shiach et al conducted a randomised crossover trial to investigate the reliability of point-of-care prothrombin time testing in a community clinic. ${ }^{11}$ Patient satisfaction was a secondary outcome. They reported that patients were very satisfied with the amount of information given by staff; $98 \%$ of patients conveyed a preference for a community-based anticoagulant clinic and no patient expressed a preference for attending the hospital. Chaudry et al, who investigated patient satisfaction with registered nurse-managed point-of-care international normalised ratio (INR) testing in primary care found that the majority of patients $(79 \%)$ significantly preferred the point-of-care INR method of testing. ${ }^{8}$

The trial results showed no treatment group difference in patient views regarding outside pathology laboratories involving extra time and transport costs. There have been conflicting results from previous studies. Supporting the trial findings, a RCT conducted by Stone et al found that patients were not concerned with extra practice visits as they were retired, or could organise appointments to fit in with their work. ${ }^{9}$ The results in the trial reflect this, as over $54 \%$ of trial patients were retired. However, Cohen et al, who investigated patient attitudes to point-of-care testing for hyperlipidaemia, reported that two-thirds $(67 \%)$ of the patient sample indicated that attending an outside pathology laboratory involved extra time and transport costs, yet 39\% did not mind going. ${ }^{4}$ The average level of agreement with the statement that laboratories have better hygiene was significantly higher in the control group compared to the intervention group.

For patients on anticoagulant therapy, differences in satisfaction between the intervention and control group in terms of the collection process, convenience, and disease management were larger compared to patients with diabetes or hyperlipidaemia. This suggests that point-of-care testing offers this group, who require more frequent testing, a positive and acceptable alternative to laboratory testing.

\section{Implications for future research and clinical practice}

To maximise the success of programmes/ interventions aimed at improving clinical outcomes, patient satisfaction and acceptability should be evaluated. The growing body of evidence suggests that not only should health care be evidence based, but it is necessary for health systems to be responsive and integrate what people want, to optimise patient health outcomes. ${ }^{13}$ Involving patients in their care and providing services that enhance the experience of the doctor-patient relationship can positively influence health outcomes. ${ }^{14}$ Additionally, there is evidence that satisfaction is linked to improved care and greater adherence to management recommendations. ${ }^{15,16}$ The results from the trial reported here have shown that point-of-care testing was not only acceptable but led to positive outcomes in terms of patient medication adherence ${ }^{17}$ and improved therapeutic control, ${ }^{3}$ providing evidence that point-of-care testing in the general practice setting can be used as an effective alternative to pathology laboratory testing.

\section{Funding body}

This trial was funded by the Australian Department of Health and Ageing through the Pathology Section, Diagnostics Services Branch

\section{Ethics committee}

The trial was approved by five independent Australian 
research ethics committees: The University of Adelaide Human Research Ethics Committee; Departmental Ethics Committee, Department of Health and Ageing; Human Research Ethics Committee, The University of Sydney; The Standing Committee on Ethics in Research Involving Humans, Monash University; and the National Research and Evaluation Ethics Committee, Royal Australian College of General Practitioners (RACGP)

\section{Competing interests}

The authors have stated that there are none

\section{Acknowledgements}

The members of the Point of Care Testing in General Practice Trial Management Committee included Justin Beilby, Janice Gill, Briony Glastonbury, Roger Killeen, Pamela McKittrick, Caroline Laurence, Mark Shephard, Andrew St John, David Thomas, Phil Tideman, Rosy Tirimacco, and Paul Worley.

\section{Discuss this article}

Contribute and read comments about this article on the Discussion Forum: http://www.rcgp.org.uk/bjgp-discuss

\section{REFERENCES}

1. Price C, St John A. Point-of-care testing. 2nd edn. Washington DC: AACC Press, 2004.

2. Laurence C, Gialamas A, Yelland L, et al. A pragmatic cluste randomised controlled trial to evaluate the safety, clinical effectiveness, cost effectiveness and satisfaction with point of care testing in a general practice setting - rationale, design and baseline characteristics. Trials 2008; 9: 50 .

3. Bubner T, Laurence C, Gialamas A, et al. Effectiveness of point-ofcare testing for therapeutic control of chronic conditions: results from the PoCT in General Practice Trial. Med J Aust 2009; 190(11): 624-626.

4. Cohen J, Piterman L, McCall L, Segal L. Near-patient testing for serum cholesterol: attitudes of general practitioners and patients, appropriateness, and costs. Med J Aust 1998; 168(12): 605-609.

5. Gillam S, Freedman D, Naughton B, et al. An evaluation of near patient testing in general practice. J Eval Clin Pract 1998; 4(2): 165-169.
6. Shephard M. Cultural and clinical effectiveness of the 'QAAMS point-of-care testing model for diabetes management in Australian Aboriginal medical services. Clin Biochem Rev 2006; 27(3): 161-170.

7. Shephard M, Mazzachi B, Shephard A, et al. Point-of-care testing in Aboriginal Hands - a model for chronic disease prevention and management in indigenous Australia. Point of Care. The Journal of Near-Patient Testing \& Technology 2006; 5(4): 168-176.

8. Chaudhry R, Scheitel S, Stroebel R, et al. Patient satisfaction with point-of-care international normalized ratio testing and counseling in a community internal medicine practice. Manag Care Interface 2004; 17(3): 44-46.

9. Stone M, Burden A, Burden M, et al. Near patient testing for glycated haemoglobin in people with type 2 diabetes mellitus managed in primary care: acceptability and satisfaction. Diabet Med 2007; 24(7): 792-795.

10. Grieve R, Beech R, Vincent J, Mazurkiewicz J. Near patient testing in diabetes clinics: appraising the costs and outcomes. Health Technol Assess 1999; 3(15): 1-74

11. Shiach C, Campbell B, Poller L, et al. Reliability of point-of-care prothrombin time testing in a community clinic: a randomized crossover comparison with hospital laboratory testing. $\mathrm{Br} \mathrm{J}$ Haemotol 2002; 119(2): 370-375.

12. Box G, Cox D. An analysis of transformations. J Roy Stat Soc Series B Methodol 1964; 26(2): 211-252.

13. World Health Organization. The world health report 2008: primary health care now more than ever. Geneva: Switzerland, 2008:1-119. http://www.who. int/whr/2008/en/index.html (acessed 22 Jan 2010).

14. Tabrizi J, Wilson A, Coyne E, O'Rourke P. Clients' perspective on service quality for type 2 diabetes in Australia. Aust N Z J Public Health 2007; 31(6): 511-515.

15. Alazri M, Neal R. The association between satisfaction with services provided in primary care and outcomes in Type 2 diabetes mellitus. Diabet Med 2003; 20(6): 486-490.

16. Kerse N, Buetow S, Mainous A, et al. Physician-patient relationship and medication compliance: a primary care investigation. Ann Fam Med 2004; 2(5): 455-461.

17. Gialamas A, Yelland LN, Ryan P, et al. Does point-of-care testing lead to the same or better adherence to medication? A randomised controlled trial: the PoCT in General Practice Trial. Med J Aust 2009; 191(9): 487-491 